\title{
Experimental Study of Dowel Bar Alternatives Based on Similarity Model Test
}

\author{
Chichun Hu, ${ }^{1}$ Jiexian Ma, ${ }^{1}$ Jianying Zhao, ${ }^{1}$ Zhen Leng, ${ }^{2}$ and Denis Jelagin ${ }^{3}$ \\ ${ }^{1}$ College of Civil and Transportation Engineering, South China University of Technology, Guangzhou 510641, China \\ ${ }^{2}$ Department of Civil and Environmental Engineering, The Hong Kong Polytechnic University, Hung Hom, Kowloon, Hong Kong \\ ${ }^{3}$ Division of Highway and Railway Engineering, KTH Royal Institute of Technology, 10044 Stockholm, Sweden
}

Correspondence should be addressed to Chichun Hu; cthu@scut.edu.cn

Received 2 November 2016; Accepted 19 January 2017; Published 15 February 2017

Academic Editor: Hainian Wang

Copyright (C) 2017 Chichun Hu et al. This is an open access article distributed under the Creative Commons Attribution License, which permits unrestricted use, distribution, and reproduction in any medium, provided the original work is properly cited.

\begin{abstract}
In this study, a small-scaled accelerated loading test based on similarity theory and Accelerated Pavement Analyzer was developed to evaluate dowel bars with different materials and cross-sections. Jointed concrete specimen consisting of one dowel was designed as scaled model for the test, and each specimen was subjected to 864 thousand loading cycles. Deflections between jointed slabs were measured with dial indicators, and strains of the dowel bars were monitored with strain gauges. The load transfer efficiency, differential deflection, and dowel-concrete bearing stress for each case were calculated from these measurements. The test results indicated that the effect of the dowel modulus on load transfer efficiency can be characterized based on the similarity model test developed in the study. Moreover, round steel dowel was found to have similar performance to larger FRP dowel, and elliptical dowel can be preferentially considered in practice.
\end{abstract}

\section{Introduction}

The performance of jointed concrete pavements is often closely related to the load transfer capacity of dowel bars at the pavement joints. Faulting is frequently seen in the pavement joints without dowel bars, because the load transfer provided by aggregate interlock alone is insufficient. Steel dowels are commonly used to enhance load transfer in the concrete pavements. However, the issue of high bearing stress and corrosion of steel dowel has a significant impact on their long-term performance [1]. There have been efforts to improve dowel durability through the use of alternate shapes (other than round) to further reduce dowel-concrete bearing stresses and to use alternative materials for improved corrosion resistance [2-8]. Among those alternative materials, fiber reinforced polymer (FRP) dowel bars have been given considerable attention because of their excellent corrosion resistance.

Usually, the laboratory experiments of dowel bar include static and fatigue elemental shear, bending strength, accelerated loading test, pull-out, alkalinity aging, and chemical properties [9]. Due to the relative low cost and time consumption and relative high reliability, evaluation of joint performance and dowel alternatives using laboratory accelerated loading has been conducted in the past 20 years.

Among those researchers, Buch and Zollinger conducted a laboratory study to evaluate the dowel looseness across a saw-cut joint using concrete specimens with dimension of $610 \mathrm{~mm} \times 254 \mathrm{~mm} \times 915 \mathrm{~mm}$ [10]. The fatigue load application system consisted of a pair of hydraulic rams that pulsated alternately on either side of the joint to produce loads of up to a maximum of $40 \mathrm{kN}$, which can closely simulate that of a truck tire loading a joint. The total duration of the load and unload cycle was 1.5 seconds, of which the rest period lasted for 0.98 seconds. Melhem and Sheffield studied the performance of FRP and steel dowels in jointed slabs using a pulse load system [11]. Both slabs, the one with steel dowels and the one with FRP dowels, were tested side-by-side such that load was applied simultaneously. The load was applied by each actuator in a sinusoidal-shape function, with the two functions 180 degrees out of phase. Using this setup a speed of 9000 applications per hour can be achieved which 
TABLE 1: Modulus test result of rubber bearing.

\begin{tabular}{lcccc}
\hline Sequence & Force $(\mathrm{kN})$ & Displacement $(\mathrm{mm})$ & Strain & Modulus $(\mathrm{MPa})$ \\
\hline Preloading & 45 & & & \\
1 & 90 & 0.14925 & 0.0074625 & 134.00 \\
2 & 135 & 0.34425 & 0.0172125 & 116.19 \\
3 & 180 & 0.55375 & 0.0276875 & 108.35 \\
4 & 225 & 0.83725 & 0.0418625 & 95.55 \\
\hline Average & & & & 113.53 \\
\hline
\end{tabular}

is 15 times faster than the rolling axles. Bian and Harvey utilized the second generation of the Minnesota Accelerated Loading Facility (MinneALF-2) to study two jointed test pavement specimens that incorporate two different dowels [12]. The MinneALF-2 simulates vehicle loads traveling across pavement joints by means of two hydraulic actuators. The loading pattern for each actuator is a combination of a sinusoidal impulse (90 degrees out of phase for two actuators) and a small preload. Khazanovich et al. evaluated FRP dowel bars spaced at different intervals as load transferring devices in Jointed Plain Concrete Pavement (JPCP) under HS25 static and fatigue loads [13]. Five different concrete specimens with dimensions of 30.48 by 30.48 by $304.8 \mathrm{~cm}$ were cast for tests. Pavement load was applied on one side of the joint using a $244.65-\mathrm{kN}$ hydraulic actuator system through a controller. Vijay et al. performed Heavy Vehicle Simulator (HVS) tests of several types of dowels at Palmdale's dowel bar retrofitted concrete pavement test sections [14]. Channelized, bidirectional loading was conducted on the wheel path over the center of the dowel group. The results showed that four epoxy-coated steel dowels per wheel path had much smaller joint vertical deflections than the alternatives (four FRP dowels, four hollow stainless steel dowels).

As mentioned above, the pulse load system can significantly shorten duration of time while HVS can exactly replicate the rolling wheel effects. But both of them need specialized equipment, which limits the laboratory study and practical application of dowel alternatives. The object of this research is to develop a small-scale accelerated loading test to evaluate dowel alternatives. Therefore, a similarity model test combining the advantages of pulse load system and HVS was introduced; the corresponding test program was described, and dowel bars with different materials and cross-sections were evaluated.

\section{Model Design}

A JPCP consisting of slabs $26 \mathrm{~cm}$ thick and $4.2 \mathrm{~m}$ wide is considered in this paper. Elasticity modulus $E_{c}$ and Poisson's ratio $\mu_{c}$ of PCC slab is $31 \mathrm{GPa}$ and 0.15 , respectively. An axle load consisting of two identical tires $1.8 \mathrm{~m}$ apart, each carrying $50 \mathrm{kN}$, is applied at the edge of the joint, $15 \mathrm{~cm}$ from the edge of the slab. The total shear load carried by dowel group is assumed to be 50 percent of the applied load, which means only $25 \mathrm{kN}$ shear load will be transferred by dowels within the radius of effective length $l_{\text {eff }}$. As the mid-panel load is carried by more dowels than the edge load, the critical dowel is the edge dowel. Before calculation of the effective length of load distribution, the modulus of subgrade reaction should be determined first.

2.1. Foundation Support. Using accelerated loading test to evaluate joint performance, the following factors should be considered: dowels, aggregate interlock, and base/subgrade reaction [15]. However, since the emphasis of this research was to compare dowel bar alternatives, rubber bearing was used to simulate the foundation support of JPCP, which could eliminate the effect of accumulated deformation and erosion of the supporting base or subgrade material. The modulus test result of rubber bearing $E_{\mathrm{rb}}$ is shown in Table 1 .

In the similarity model test, the value of elastic modulus similarity constant $C_{E}$ is taken as 1 . Hence, the elastic modulus of the subgrade is

$$
E_{s}=C_{E} E_{\mathrm{rb}}=E_{\mathrm{rb}}=113.53 \mathrm{MPa} .
$$

And the modulus of subgrade reaction $k$ is computed by the most commonly used expression for the relationship between $k$ and $E_{s}[17,18]$ :

$$
k=\left(\frac{E_{s}}{E_{c}}\right)^{1 / 3} \frac{E_{s}}{\left(1-\mu_{s}^{2}\right) h}=0.0801262 \mathrm{MPa} / \mathrm{mm},
$$

where $h$ is the thickness of the concrete slab and $\mu_{s}$ is the Poisson ratio of the subgrade, which is 0.4 .

2.2. Load Distribution. The radius of relative stiffness $l_{r}$ of the pavement-foundation system is calculated as follows [19]:

$$
l_{r}=\sqrt[4]{\frac{E_{c} h^{3}}{12 k\left(1-\mu_{c}^{2}\right)}}=87.3 \mathrm{~cm}
$$

where $\mu_{c}$ is the Poisson ratio of the concrete slab.

Tabatabaie et al. modeled a doweled joint using finite element showing that an effective length of $1.0 l_{r}$ is more appropriate for today's construction practices [20]. Considering scaled model in this research cannot exactly simulate the boundary condition of the pavement slab, the effective length of load distribution is taken as $0.9 l_{r}$ to reflect the weakened boundary condition:

$$
l_{\mathrm{eff}}=0.9 l_{r}=78.6 \mathrm{~cm} \text {. }
$$

Hence, the shear force transferred by the critical dowel can be obtained, which is $13.47 \mathrm{kN}$. Detail of the load distribution of dowel bars is shown in Figure 1. 


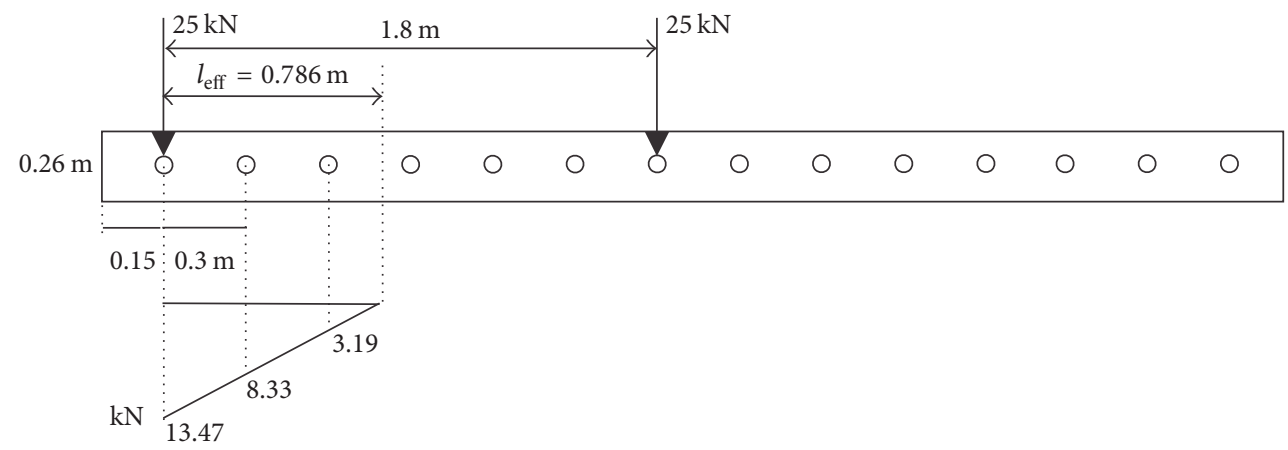

FIGURE 1: Load diagram at pavement joint.

TABLE 2: Similarity constant.

\begin{tabular}{lc}
\hline & Similarity constant \\
\hline Length & $C_{l}=3.5$ \\
Deflection & $C_{w}=3.5$ \\
Elastic modulus & $C_{E}=1$ \\
Strain & $C_{\varepsilon}=1$ \\
Applied load & $C_{F}=C_{E} C_{l}^{2}=12.25$ \\
\hline
\end{tabular}

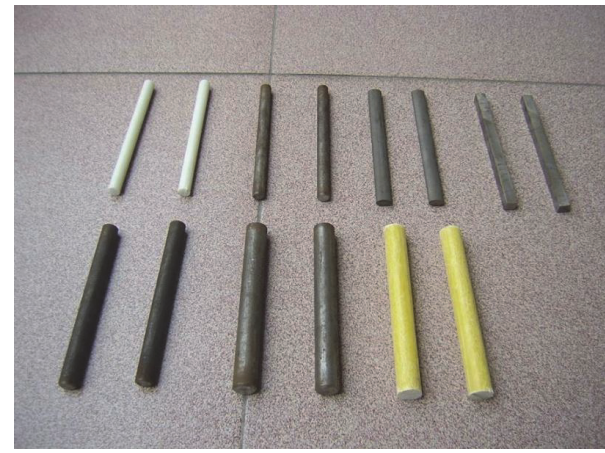

Figure 2: Dowel bars with different materials and shapes.

2.3. Similarity Constant. In order to decrease the scale of concrete slab and make the accelerated loading test easier to perform in the lab, the prototype of the similarity model test is only part of the pavement slab. The value of length similarity constant $C_{l}$ is taken as 3.5, and the load similarity constant can be derived, as shown in Table 2. Parameters of prototype and scaled model are presented in Table 3.

2.4. Dowel Bars. In the experiment, steel dowels and FRP dowels are considered, and the cross-sections of the dowel bars are round, elliptical, and square (see Table 4 and Figure 2). Among them, $\phi 10$ round steel bar, square steel bar $(8.9 \mathrm{~mm} \times 8.9 \mathrm{~mm}$ ), and elliptical steel bar (major axis $=12.5 \mathrm{~mm}$, minor axis $=8 \mathrm{~mm}$ ) have the same cross-section area, so as to evaluate the optimal cross-section with respect to the same material consumption.

A nonstandard third point bending test and a double shear test were performed to evaluate the bending capacity

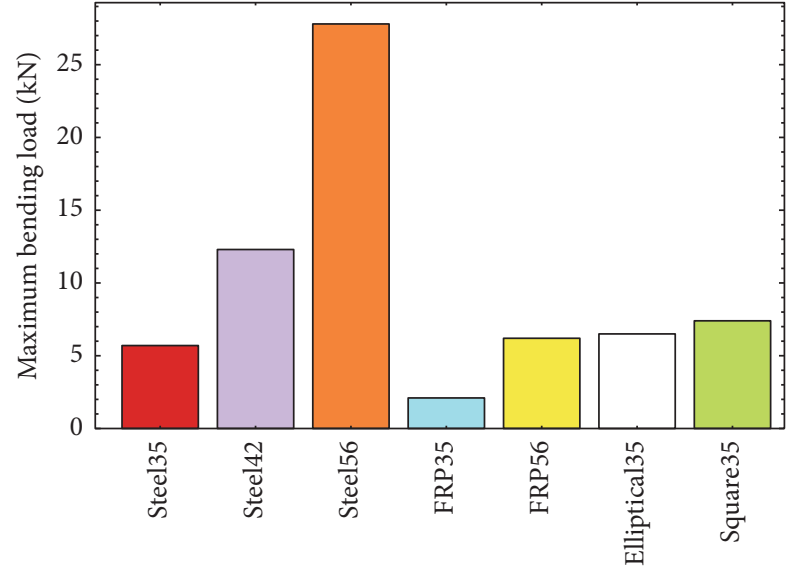

Figure 3: Maximum bending load for different dowels.

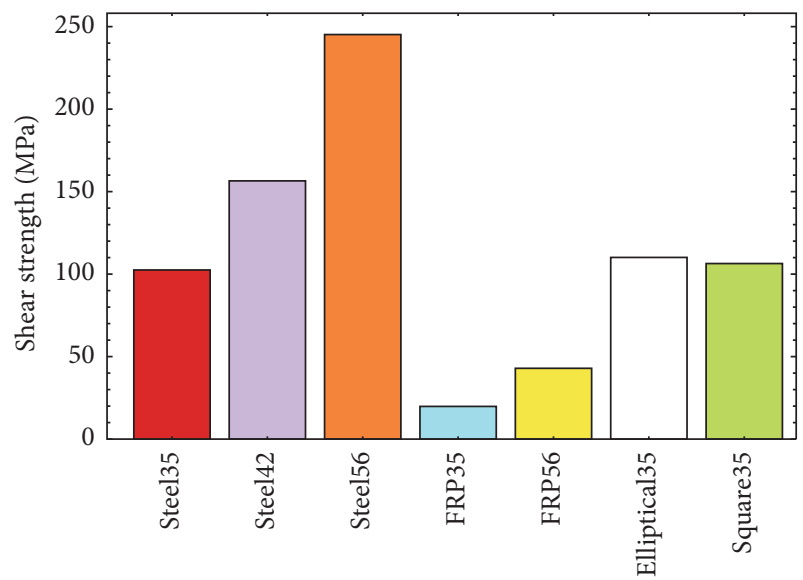

FIGURE 4: Shear strength for different dowels.

and shear strength of the scaled dowel bar. The test results are presented in Figures 3 and 4. As can be seen in these figures, under the condition of the same material and cross-section area, the bending failure force of the square steel bar is the largest, followed by the elliptical steel bar, and the round steel bar is the lowest. As for shearing test, the shear strengths of steel bars with different cross-sections are very close, and the difference is no more than $7 \%$. In addition, the comparison 
TABLE 3: Parameters of prototype and scaled model.

\begin{tabular}{lcc}
\hline & Prototype & Scaled model \\
\hline Length of concrete slab $(\mathrm{mm})$ & 520 & 148.5 \\
Width of concrete slab $(\mathrm{mm})$ & 437.5 & 125 \\
Thickness of concrete slab $(\mathrm{mm})$ & 262.5 & 75 \\
Joint width $(\mathrm{mm})$ & 10 & 2.9 \\
Dowel length $(\mathrm{mm})$ & 450 & 129 \\
Applied load $(\mathrm{kN})$ & 13.47 & 1.1 \\
\hline
\end{tabular}

TABLE 4: Material, cross-section, and size of dowels.

\begin{tabular}{|c|c|c|c|c|c|}
\hline \multirow{2}{*}{ Material } & \multirow{2}{*}{ Cross-section } & \multirow{2}{*}{ Code } & \multirow{2}{*}{ Prototype size $(\mathrm{mm})$} & \multicolumn{2}{|c|}{ Scaled Model } \\
\hline & & & & Dimensions $(\mathrm{mm})$ & Cross-section area $\left(\mathrm{mm}^{2}\right)$ \\
\hline \multirow{3}{*}{ Steel } & \multirow{3}{*}{ Round } & Steel35 & $\phi 35$ & $\phi 10$ & 80 \\
\hline & & Steel42 & $\phi 42$ & $\phi 12$ & 110 \\
\hline & & Steel56 & $\phi 56$ & $\phi 16$ & 200 \\
\hline \multirow{2}{*}{ FRP } & \multirow{2}{*}{ Round } & FRP35 & $\phi 35$ & $\phi 10$ & 80 \\
\hline & & FRP56 & $\phi 56$ & $\phi 16$ & 200 \\
\hline \multirow{2}{*}{ Steel } & \multirow{3}{*}{$\begin{array}{l}\text { Major axis } \\
\text { Minor axis } \\
\end{array}$} & \multirow{2}{*}{ Elliptical35 } & 43.8 & 12.5 & \multirow{2}{*}{80} \\
\hline & & & 28 & 8 & \\
\hline Steel & & Square 35 & $31.2 \times 31.2$ & $8.9 \times 8.9$ & 80 \\
\hline
\end{tabular}

TABLE 5: Sensitivity analysis of dowels in the prototype (computed using Friberg's bearing stress analysis).

\begin{tabular}{lccccc}
\hline Code & Dowel modulus $(\mathrm{GPa})$ & Joint Deflection at joint face $(\mathrm{mm})$ & Bearing stress $(\mathrm{MPa})$ & $M_{\max }(\mathrm{N} \cdot \mathrm{m})$ & $\varepsilon_{\max }\left(10^{-6}\right)$ \\
\hline Steel35 & 210 & 0.0460 & 18.71 & -243.9 & -276 \\
Steel42 & 210 & 0.0330 & 13.43 & -272.7 & -179 \\
Steel56 & 210 & 0.0196 & 7.98 & -327.1 & -90 \\
FRP35 & 40 & 0.0731 & 29.75 & -177.6 & -1055 \\
FRP56 & 40 & 0.0308 & 12.52 & -232.1 & -337 \\
Elliptical35 & 210 & 0.0442 & 17.99 & -213.7 & -302 \\
Square35 & 210 & 0.0490 & 19.95 & -253.2 & -238 \\
\hline
\end{tabular}

of the FRP dowel to the steel dowel with the same area shows that the shear strength of the FRP dowel is about 1/5 of the steel dowel while the bending capacity of the FRP dowel is about $1 / 3$.

Joint deflection, dowel-concrete bearing stress and maximum strain of different types of dowels were computed using Friberg's bearing stress analysis [21], to evaluate the influence of materials and cross-sections on the behavior of dowel load transfer system, assuming that the shear force $P_{c}$ carried by the critical dowel was $13.47 \mathrm{kN}$ and the modulus of dowel support $K_{0}$ was $407 \mathrm{MPa} / \mathrm{mm}$. The results are presented in Table 5. As shown in Table 5, the elliptical dowel can reduce dowel-concrete bearing stress compared to the round steel bar of the same cross-section area, which is very important in controlling the development of dowel looseness [8]. Square dowel is expected to reduce joint deflection and bearing stress in this research. However, the theoretical calculation does not agree with the expectation.

\section{Model Manufacture}

As shown in Figure 5, the mold of the scaled model consists of expansion joint plate, support of dowel bar, removable ears, rubber bearing, and connecting steel bar. The connecting steel bar is used to simulate the boundary condition of the prototype. Before making specimen, vaseline was smeared in the inner wall of the formworks to prevent leaking.

All the FRP dowels and steel dowels were instrumented with strain gauges to monitor strains on dowel bars. The strain gauges were located on the top and bottom of the dowel bars on both sides, at a distance of $1.2 \mathrm{~cm}$ from the centerline of the $13 \mathrm{~cm}$ long dowel bars (see Figure 6). Strain gauges are temperature compensated by using the dummy gauge technique. A dummy gauge is wired into a Wheatstone bridge on an adjacent arm to the active gauge so that the temperature effects on the active and dummy gauges counteract each other. 


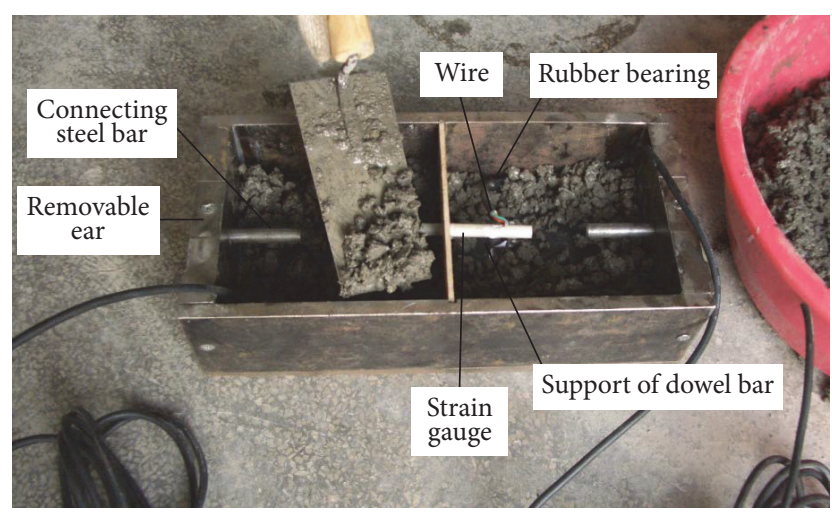

Figure 5: Placing concrete into the formwork.

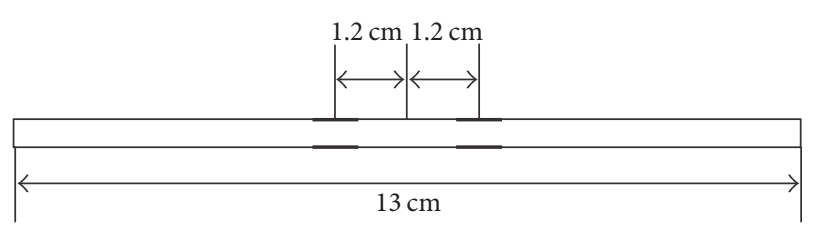

FIGURE 6: The strain location on the dowel bar.

\section{Test Program}

In the scaled model, Asphalt Pavement Analyzer (APA) is used to perform small-scaled accelerated loading test. The APA tracks a loaded aluminum wheel back and forth across a pressurized linear hose over a beam sample which can simulate the traffic load of actual pavement. In this study, test molds composed of ultrahigh molecular weight polyethylene in the original APA test were removed and the wheel was tracked across the specimen for 864,000 cycles using a 1113 $\pm 4.5 \mathrm{~N}$ load and a $200 \mathrm{MPa}$ hose pressure. Specimens with a dimension of $75 \mathrm{~mm} \times 125 \mathrm{~mm} \times 300 \mathrm{~mm}$ were prepared and DH3817 dynamic strain acquisition system was used. Steel holding fixtures were applied to both ends of the specimens, which allowed no displacement in the horizontal direction.

The procedure of accelerated loading test is as follows. (1) Preheat specimens preheated at the test temperature $\left(30^{\circ} \mathrm{C}\right)$ in oven for $3 \mathrm{~h}$. (2) Set the hose pressure and load cylinder pressure to the desired levels. (3) Stabilize the testing chamber temperature at the test temperature. (4) Secure the preheated beam samples in the APA and fix the dial indicators which are mounted on each side of joint near the edge of the slab. (5) Close the chamber doors and allow a minimum of $10 \mathrm{~min}$ for the temperature to stabilize. (6) Apply 25 cycles to seat the specimens before taking the initial measurements and adjust the hose pressure as needed during these 25 cycles. (7) Clear the gauge and take initial strain and defection readings. (8) Start the test and collect the data of dowel strain and slab deflections at every 48,000 load cycles, as shown in Figures 7 and 8 .

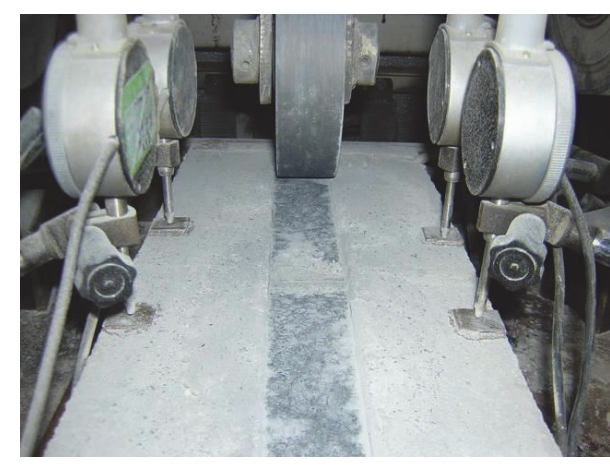

FIgURE 7: Similarity model test.

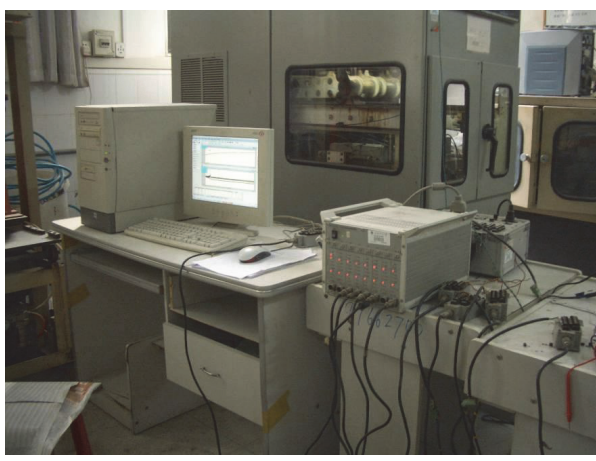

FIgURE 8: Data collection.

\section{Results and Discussion}

5.1. Load Transfer Efficiency. Load transfer efficiency (LTE) is defined as the ability of a joint or crack to transfer load from one side of the joint or crack to the other. The method used to calculate load transfer efficiency is shown in (5). A load transfer efficiency of 70 to 100 percent is typically considered adequate:

$$
\mathrm{LTE}=\frac{w_{\mathrm{UL}}}{w_{L}} 100 \%
$$

where $w_{\mathrm{UL}}$ is the deflection of unloaded slab and $w_{L}$ is the deflection of loaded slab.

The LTE and the corresponding number of wheel cycles for each type of dowel bar in the prototype are presented in Figure 9. As shown in Figure 9, the average LTE of FRP35 observed in the accelerated loading test is $87.7 \%$, which is smaller than the average LTE of Steel35, 91\%. After 864,000 cycles, the LTE of FRP35 decreased from $90.8 \%$ to $82.6 \%$, while the LTE of Steel35 decreased from $94.8 \%$ to $87 \%$, indicating that the use of FRP dowel has a significant impact on the performance of pavement joint. The main reason is that FRP dowel has much lower elastic modulus than steel dowel, typically about 20 percent, which results in significantly higher bearing stress and differential joint deflection [8].

A comparison between FRP56 and Steel42 was also conducted. The average LTE of FRP56 and Steel42 are 93.4\% 
TABLE 6: Steel dowel and FRP dowel having the same performance.

\begin{tabular}{|c|c|c|c|c|c|c|}
\hline & & \multicolumn{3}{|c|}{ Accelerated loading test } & \multirow{2}{*}{\multicolumn{2}{|c|}{$\begin{array}{c}\text { Theoretical calculation using } \\
\text { Friberg's bearing } \\
\text { stress analysis }\end{array}$}} \\
\hline & & $\begin{array}{l}\text { Melham and Sheffield } \\
\text { pulse load system [11] }\end{array}$ & $\begin{array}{l}\text { Embacher et al. } \\
\text { full-scale repeated } \\
\text { load test [16] }\end{array}$ & $\begin{array}{l}\text { Similarity } \\
\text { model test }\end{array}$ & & \\
\hline \multirow{2}{*}{ Diameter } & Steel & $\begin{array}{c}1 \mathrm{in} \\
(25.4 \mathrm{~mm})\end{array}$ & $\begin{array}{c}1.5 \mathrm{in} \\
(38.1 \mathrm{~mm})\end{array}$ & $\begin{array}{l}1.65 \mathrm{in} \\
(42 \mathrm{~mm})\end{array}$ & $\begin{array}{c}1.5 \mathrm{in} \\
(38.1 \mathrm{~mm})\end{array}$ & $\begin{array}{c}1.65 \mathrm{in} \\
(42 \mathrm{~mm})\end{array}$ \\
\hline & FRP & $\begin{array}{c}1.5 \mathrm{in} \\
(38.1 \mathrm{~mm})\end{array}$ & $\begin{array}{c}2 \text { in } \\
(50.8 \mathrm{~mm})\end{array}$ & $\begin{array}{c}2.2 \mathrm{in} \\
(56 \mathrm{~mm})\end{array}$ & $\begin{array}{c}1.91 \mathrm{in} \\
(48.5 \mathrm{~mm})\end{array}$ & $\begin{array}{c}2.13 \mathrm{in} \\
(54 \mathrm{~mm})\end{array}$ \\
\hline
\end{tabular}

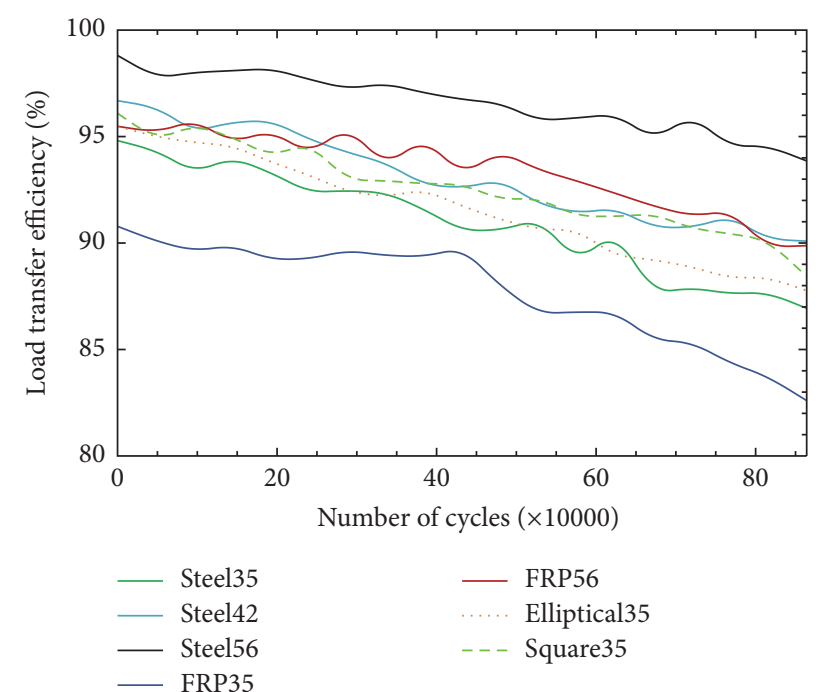

FIgURE 9: Load transfer efficiency on load cycles for different dowels.

and $93.1 \%$, respectively, which means those two have very close load transfer performance. Larger FRP dowel is a feasible solution for the above-mentioned phenomenon. The laboratory accelerated loading test results of other researchers are summarized in Table 6. Due to the difference in dowel diameter for different researchers, the effectiveness of the similarity model test cannot be verified directly. Nevertheless, the result of the theoretical calculation using Friberg's bearing stress analysis does indicate that the similarity model test can characterize the effect of the difference in dowel modulus on load transfer efficiency.

For the joints with Steel35, Steel42 and Steel56, the average LTE is $91 \%, 93.1 \%$, and $96.6 \%$, respectively. It indicates that the dowel diameter strongly influences the load transfer capability and it is very reasonable for Chinese specification to increase the dowel diameter. The results also show that the average LTE of Steel35, Elliptical35, and Square35 is $91.0 \%$, $91.6 \%$, and $92.6 \%$, respectively.

5.2. Differential Deflection. As LTE does not take into account the magnitude of deflections, it is necessary to calculate differential deflection ( $\mathrm{DD}=w_{L}-w_{\mathrm{UL}}$ ) for better understanding of LTE effectiveness [6]. Different magnitudes of differential deflection can result in the same LTE value since LTE is simply a ratio of the corner deflection of unloaded slab divided by that of loaded slab. The result of differential

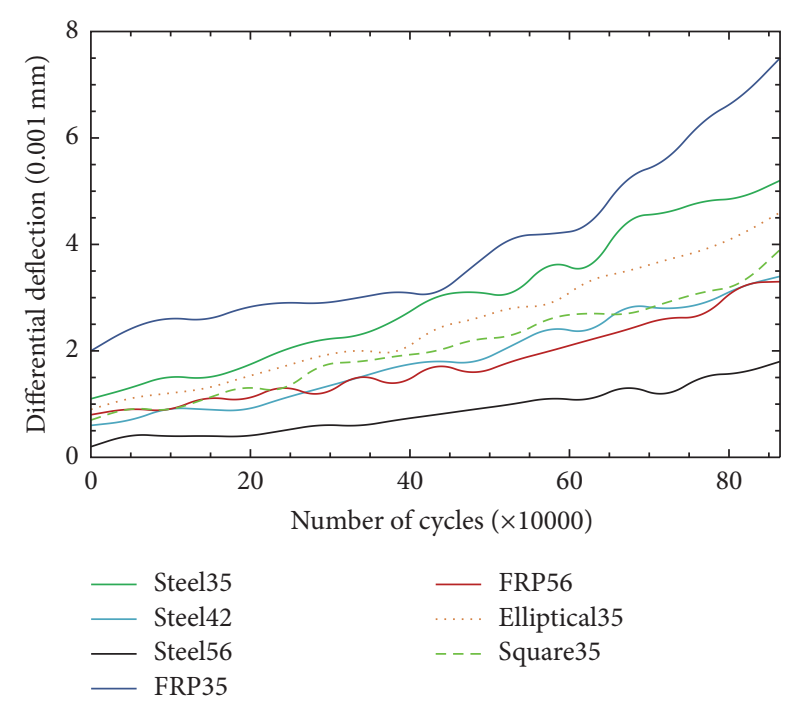

FIGURE 10: Differential deflection on load cycles for different dowels.

deflection for joints with different dowels, shown in Figure 10, revealed that combining differential deflection to interpret the effectiveness of load transfer system is necessary, especially for those having similar LTE. It can be also observed that the slope of differential deflection curve varied with material, shape, and size of dowel bar. The main reason for this is the difference in dowel-concrete bearing stress, which is responsible for the development of dowel looseness and subsequent joint deflections. In this research, elliptical dowel was used to reduce bearing stress by presenting a larger bearing surface while holding constant cross-sectional area. As expected, Elliptical35 was found to have slightly better long-term load transfer performance than Steel35, though Elliptical35 has lower bending stiffness than Steel35.

5.3. Differential Energy. The differential energy (DE) is defined as the energy difference in the elastic subgrade deformation under the loaded slab and unloaded slab [22]. MEPDG faulting models are highly dependent on the magnitude of the differential energy density at the slab corner. As DE increases, the potential for pumping and faulting increases greatly as well [8]. The following equation can be used to calculate DE:

$$
\mathrm{DE}=\frac{k}{2}\left(w_{L}^{2}-w_{\mathrm{UL}}^{2}\right),
$$




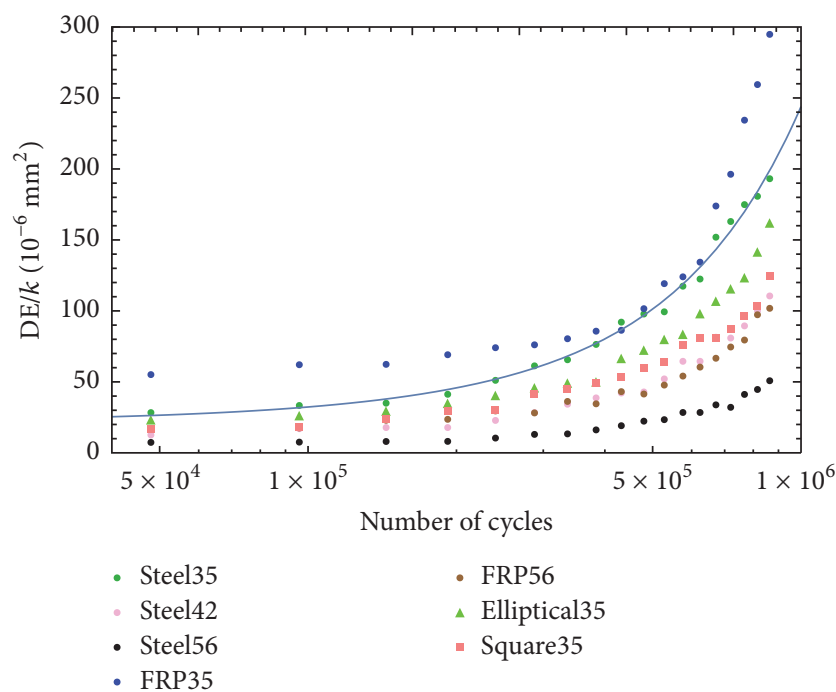

FIGURE 11: The ratio of differential energy to modulus of subgrade reaction.

where $k$ is modulus of subgrade reaction, $w_{L}$ is the corner deflection of loaded slab, and $w_{\mathrm{UL}}$ is the corner deflection of unloaded slab.

The ratio of differential elastic deformation energy to modulus of subgrade reaction, DE/ $k$, was used by Buch et al. to eliminate the impact of modulus of subgrade reaction and focus on the slab deflections [23]. In this research, DE/ $k$ was adopted to evaluate the development of differential deflection more clearly. As shown in Figure 11, the value of $\mathrm{DE} / k$ increased sharply after a certain amount of load cycles. The slope of $\mathrm{DE} / k$ after 600,000 cycles is directly related to the material, shape, and size of dowel bar, which can be selected as an indicator for dowel performance.

5.4. Deformation of Dowel Bar. Concerning the deformation of dowel bar, the strain was plotted against load cycles. The result of Steel35 and FRP35 presented in Figures 12 and 13 show that the strain of Steel35 is smaller than the strain of FRP35 under the same wheel load due to the difference in elastic modulus. Comparison of the average strains of Steel35, Steel42, and Steel56, which are 145, 105, and $60 \mu \varepsilon$, respectively, indicated that dowel bar with large diameter can effectively reduce the internal stress.

5.5. Bearing Stress. Based on Friberg's bearing stress analysis, bearing stress can be back-calculated using the test results of deflection and strain according to the following equations:

$$
\begin{aligned}
\sigma_{L} & =E_{d} \varepsilon_{L}, \\
M_{L} & =\sigma_{L} W_{z}, \\
P_{c} & =\frac{-\beta M_{L}}{e^{-\beta x_{L}}\left[\sin \beta x_{L}+(\beta z / 2)\left(\sin \beta x_{L}+\cos \beta x_{L}\right)\right]}, \\
\delta & =\frac{\lambda P_{c} z}{A G},
\end{aligned}
$$

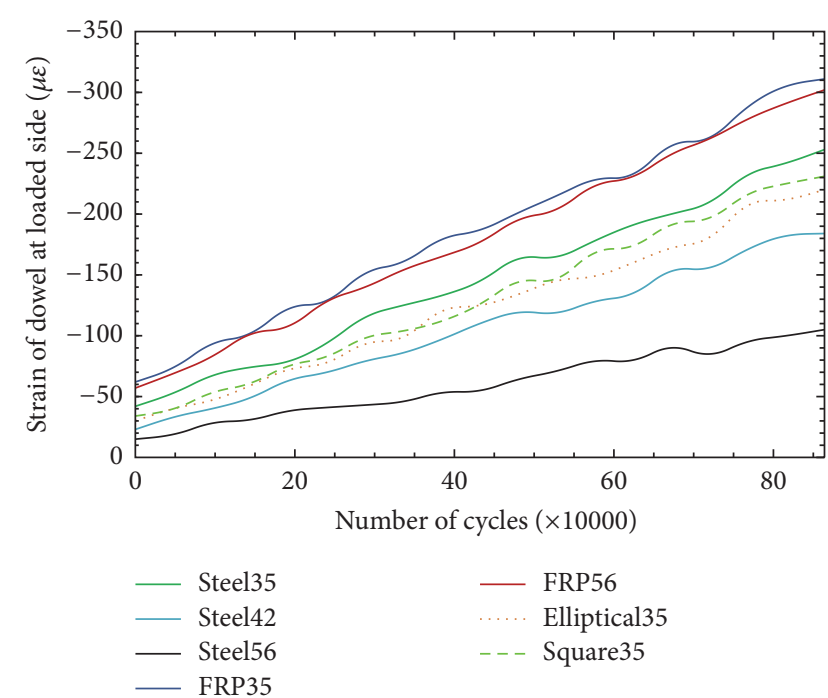

FIGURE 12: Strains of dowels at loaded sides.

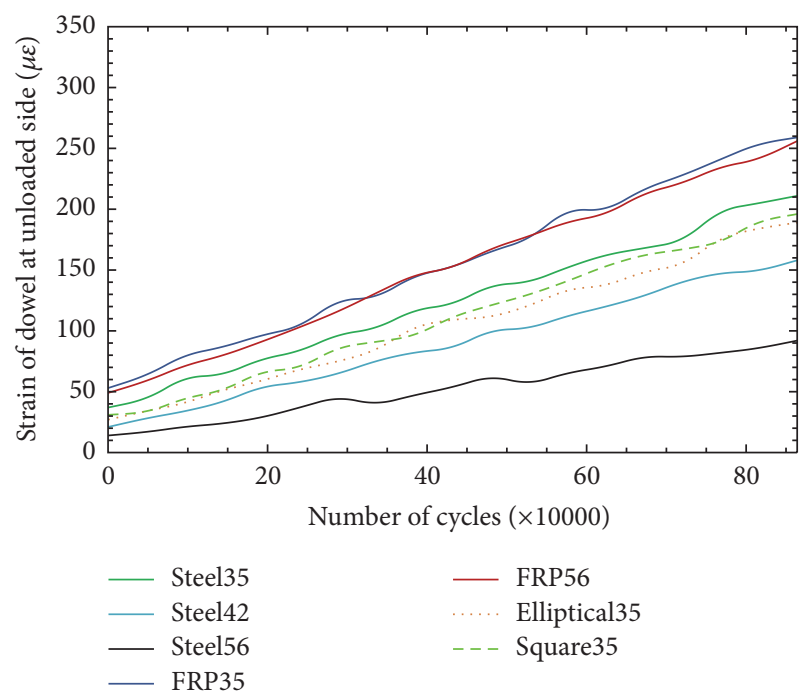

FIGURE 13: Strains of dowels at unloaded sides.

$$
\begin{aligned}
& y_{0}=\frac{\mathrm{DD}-\delta}{2}, \\
& \sigma_{b}=K_{0} y_{0},
\end{aligned}
$$

where $\sigma_{L}$ is stress of dowel where strain gauge is located, $E_{d}$ is dowel modulus, $\varepsilon_{L}$ is measured strain, $M_{L}$ is section bending moment where strain gauge located, $W_{z}$ is section modulus in bending, $P_{c}$ is shear force carried by the critical dowel, $\beta$ is relative stiffness of the dowel bar encased in concrete, $x_{L}$ is distance of strain gauge from joint face in the prototype, $z$ is joint width, $\delta$ is shear deflection, $\lambda$ is form factor, $A$ is cross-sectional area of the dowel bar, $G$ is shear modulus, $y_{0}$ is joint deflection at joint face, DD is measured differential deflection, $\sigma_{b}$ is bearing stress, and $K_{0}$ is modulus of dowel support. 


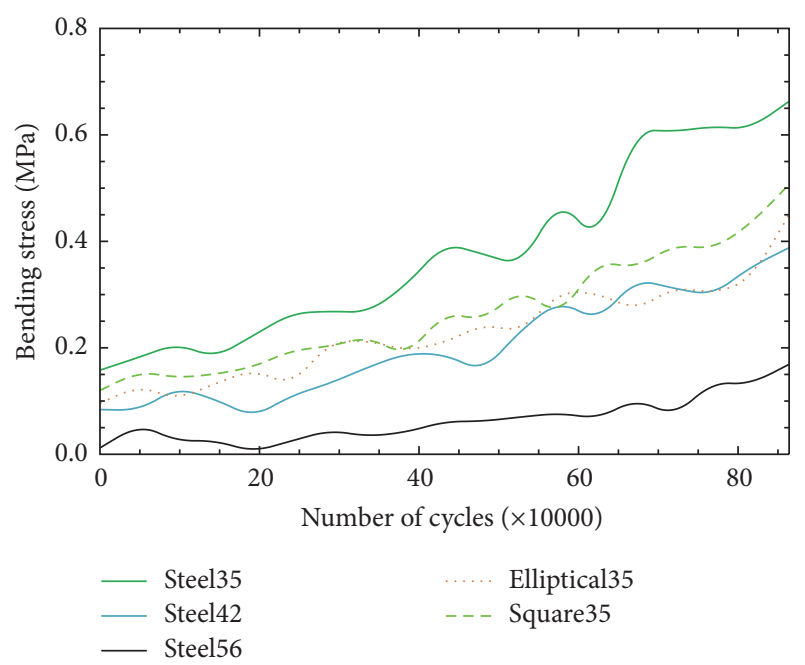

FIGURE 14: Back-calculated bearing stress.

The back-calculated bearing stress and the corresponding number of wheel cycles for steel dowel bar in the prototype are demonstrated in Figure 14. As shown in the figure, the bearing stress after 864,000 load cycles for Steel35, Elliptical35, and Square35 are $0.378 \mathrm{MPa}, 0.228 \mathrm{MPa}$, and $0.266 \mathrm{MPa}$, respectively. It is suggested that Square 35 dowel is able to reduce joint deflection and bearing stress, compared to Steel35. More research, especially field evaluation, is needed to confirm this laboratory finding.

\section{Conclusions}

The aim of this study is to develop a small-scale accelerated loading test to evaluate dowel bar alternatives, combining the advantage of pulse load system and HVS. Thus, a similarity model was developed and the corresponding test program was described. Dowel bars with different materials and crosssections were evaluated. The following conclusions can be obtained:

(1) The use of FRP dowel would lead to significantly lower LTE compared with the specimen using round steel dowel when cross-section areas were held constant. This was related to Young's modulus of FRP material which was about 80 percent lower than that of carbon steel. In the test, FRP56 and Steel42 had very close load transfer efficiency, indicating that larger FRP dowel was required when FRP dowel was used to replace steel dowel in concrete pavement.

(2) A comparison between the behaviors of the test specimens containing round steel dowel revealed that as dowel diameter increases, both differential deflection and dowel-concrete bearing stress reduce significantly which directly affects the rate of development of joint faulting. Hence, it can be concluded that dowel diameter strongly influences the load transfer behavior and performance of pavement joint.
(3) Steel dowels with round, elliptical, and square crosssections were also evaluated in this research. The results of LTE and differential deflection illustrated that Elliptical35 had slightly better long-term load transfer performance than Steel35. It can be inferred that with the continued increase of the loading cycles, the gap between the performance of two types of dowels would be more significant, considering the backcalculated bearing stress of Elliptical35 was nearly 40 percent lower than that of Steel35 after 864,000 loading cycles. In addition, square dowel was found to have outstanding load transfer capacity, even better than elliptical dowel. However, there were no relevant studies in the literature that can confirm this finding. Full-scaled accelerated loading test for square dowel should be conducted in the future.

(4) The similarity model test developed in this study is effective in characterizing the impact of dowel modulus and cross-section on load transfer capacity.

\section{Competing Interests}

The authors declare that there is no conflict of interests regarding the publication of this paper.

\section{Acknowledgments}

Support provided by National Natural Science Foundation (51308228 and 51578248), Pearl River S\&T Nova Program of Guangzhou, Chongqing Jiaotong University (LHSYS-2013002), and Guangdong DOT (2014-02-005) was greatly appreciated.

\section{References}

[1] S. R. Maitra, K. S. Reddy, and L. S. Ramachandra, "Load transfer characteristics of dowel bar system in jointed concrete pavement," Journal of Transportation Engineering, vol. 135, no. 11, pp. 813-821, 2009.

[2] J. K. Cable, "Changing the shape and location of pavement load transfer devices," Transportation Research Record, no. 1907, pp. 95-101, 2005.

[3] M. Porter and N. Pierson, "Laboratory evaluation of alternative dowel bars for use in Portland cement concrete pavement construction," Transportation Research Record, vol. 2040, pp. 80-87, 2007.

[4] C.-G. Park, C.-I. Jang, S.-W. Lee, and J.-P. Won, "Microstructural investigation of long-term degradation mechanisms in GFRP dowel bars for jointed concrete pavement," Journal of Applied Polymer Science, vol. 108, no. 5, pp. 3128-3137, 2008.

[5] M. Montaigu, M. Robert, E. A. Ahmed, and B. Benmokrane, "Laboratory characterization and evaluation of durability performance of new polyester and vinylester E-glass GFRP dowels for jointed concrete pavement," Journal of Composites for Construction, vol. 17, no. 2, pp. 176-187, 2013.

[6] C. Hu, D. Wang, K. Wang, and G. Lu, "Optimal design for the mortar-filled glass fibre-reinforced polymer tube dowels," Road Materials and Pavement Design, vol. 14, no. 4, pp. 847-863, 2013. 
[7] B. H. Al-Humeidawi and P. Mandal, "Evaluation of performance and design of GFRP dowels in jointed plain concrete pavement-part 1: experimental investigation," International Journal of Pavement Engineering, vol. 15, no. 5, pp. 449-459, 2014.

[8] M. B. Snyder, Guide to Dowel Load Transfer Systems for Jointed Concrete Roadway Pavements, National Concrete Pavement Technology Center, Ames, Iowa, USA, 2011.

[9] M. L. Porter, "Alternative dowel bars," in Proceedings of the Midcontinent Transportation Research Symposium, Ames, Iowa, USA, 2003.

[10] N. Buch and D. G. Zollinger, "Development of dowel looseness prediction model for jointed concrete pavements," Transportation Research Record, vol. 1525, pp. 21-27, 1996.

[11] H. G. Melhem and F. Sheffield, "Accelerated testing for studying pavement design and performance," Tech. Rep. FHWA-KS99-2, Kansas Department of Transportation, Manhattan, Kan, USA, 1999.

[12] Y. Bian and J. T. Harvey, "Evaluation of dowel bar retrofit alternatives using accelerated pavement testing," Transportation Research Record, vol. 1974, pp. 109-119, 2006.

[13] L. Khazanovich, I. Yut, D. Tompkins, and A. Schultz, "Accelerated loading testing of stainless steel hollow tube dowels," Transportation Research Record, no. 1947, pp. 101-109, 2006.

[14] P. V. Vijay, H. V. GangaRao, and H. Li, "Design and evaluation of jointed plain concrete pavement with fiber reinforced polymer dowels," Tech. Rep. FHWA-HRT-06-106, West Virginia University, Morgantown, WVa, USA, 2009.

[15] L. Khazanovich, M. I. Darter, and H. T. Yu, "Mechanisticempirical model to predict transverse joint faulting," Transportation Research Record, no. 1896, pp. 34-45, 2004.

[16] R. A. Embacher, M. B. Snyder, and T. D. Odden, "Using the Minnesota accelerated loading facility to test retrofit dowel load transfer systems," Transportation Research Record, vol. 1769, pp. 134-141, 2001.

[17] A. S. Vesic and S. K. Saxena, "Analysis of structural behavior of AASHO Road Test rigid pavements," NCHRP Report N.97, Highway Research Board, Washington, DC, USA, 1974.

[18] A. T. Papagiannakis and E. A. Masad, Pavement Design and Materials, John Wiley \& Sons, Hoboken, NJ, USA, 2008.

[19] H. M. Westergard, "Stresses in concrete pavements computed by theoretical analysis," Public Roads, vol. 7, no. 2, pp. 25-35, 1926.

[20] A. M. Tabatabaie, E. J. Barenburg, and R. E. Smith, "Longitudinal joint systems in slipformed rigid pavements: volume IIanalysis of load transfer systems for concrete pavements," Tech. Rep. DOT/FAA.RD-79/4, Federal Aviation Administration, U.S. Department of Transportation, Washington, DC, USA, 1979.

[21] B. F. Friberg, "Design of dowels in transverse joints of concrete pavements," Transactions of the American Society of Civil Engineers, vol. 195, no. 1, pp. 1076-1095, 1940.

[22] L. Titus-Glover, E. Owusu-Antwi, and M. I. Darter, “"Design and construction of PCC pavements, volume III: improved PCC performance," Tech. Rep. FHWA-RD-98-113, Federal Highway Administration, Washington, DC, USA, 1999.

[23] N. Buch, D. Gilliland, K. Vongchusiri, and T. J. Van Dam, "A preliminary mechanistic evaluation of PCC cross-sections using ISLAB2000-a parametric study," Research Report RC1441, Michigan State University, East Lansing, Mich, USA, 2004. 

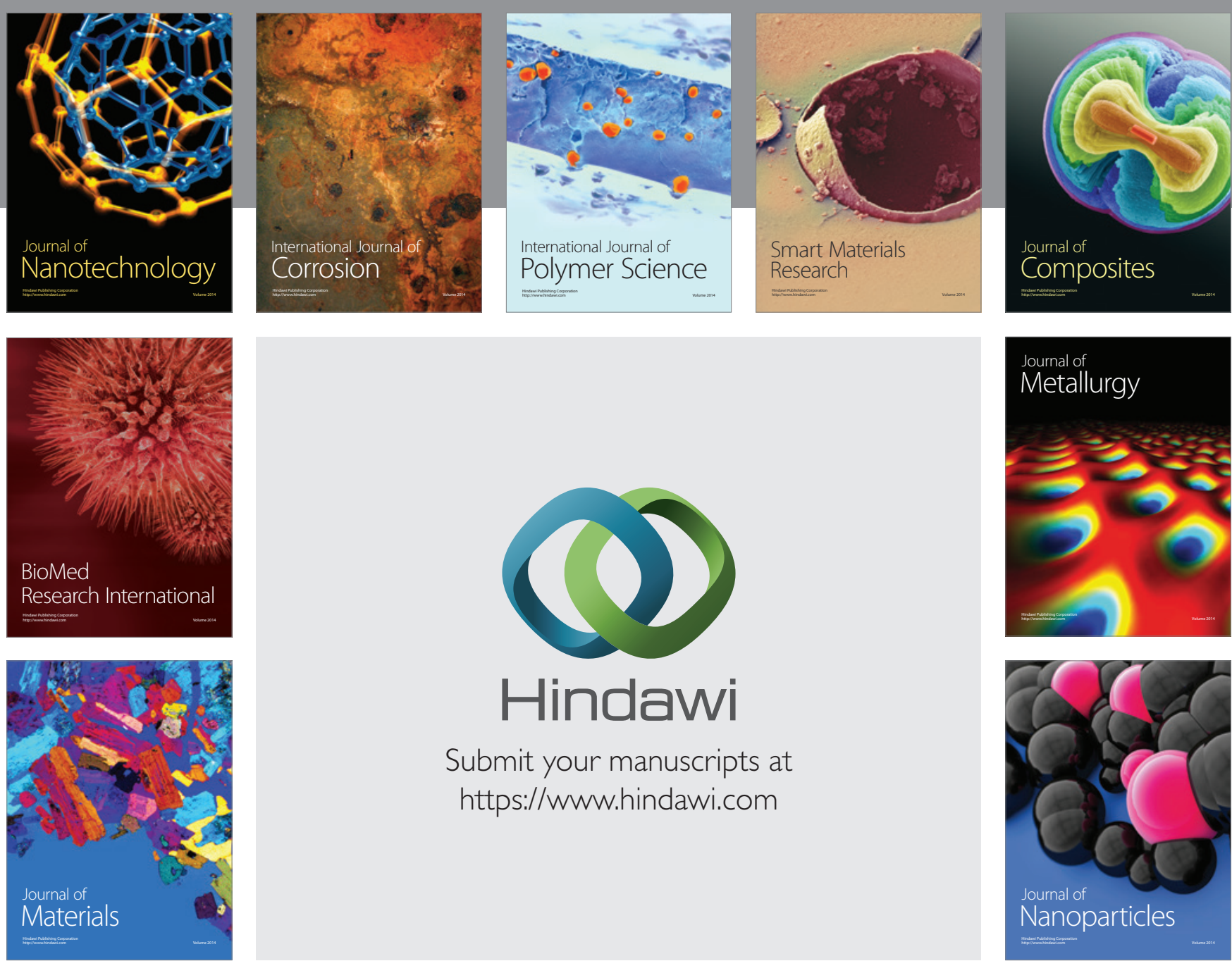

\section{Hindawi}

Submit your manuscripts at

https://www.hindawi.com

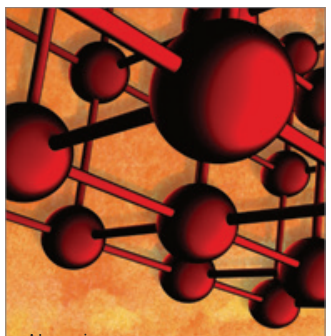

Materials Science and Engineering
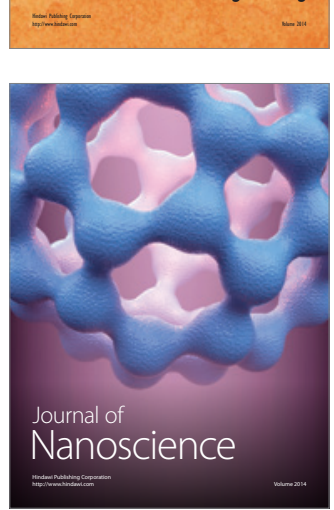
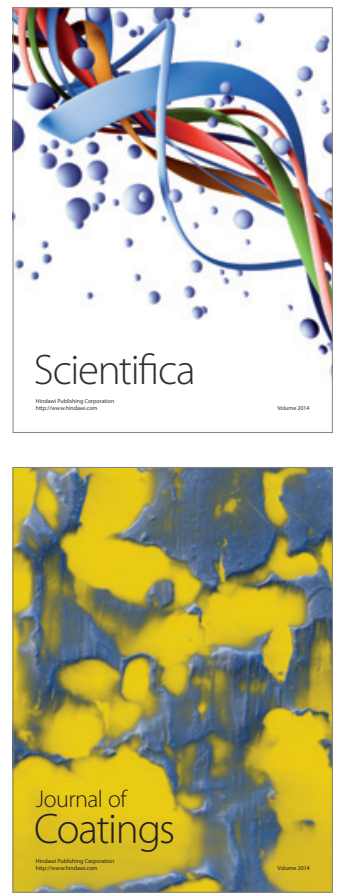
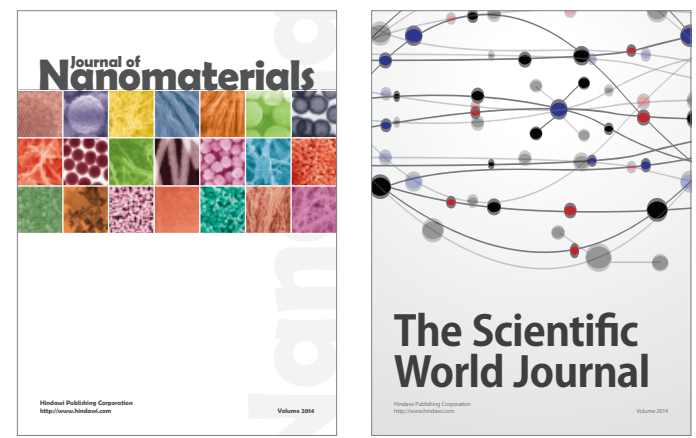

The Scientific World Journal
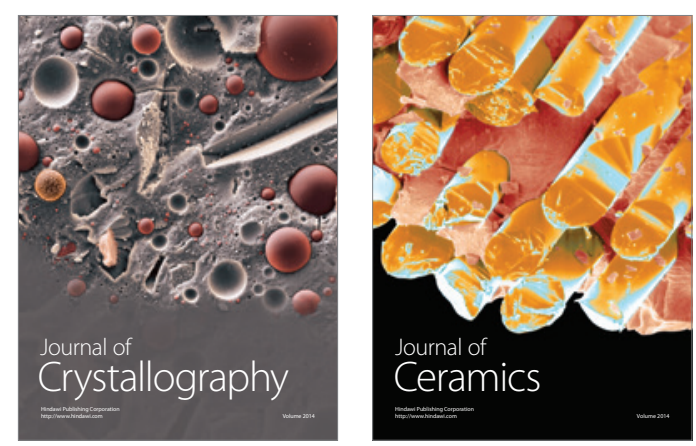
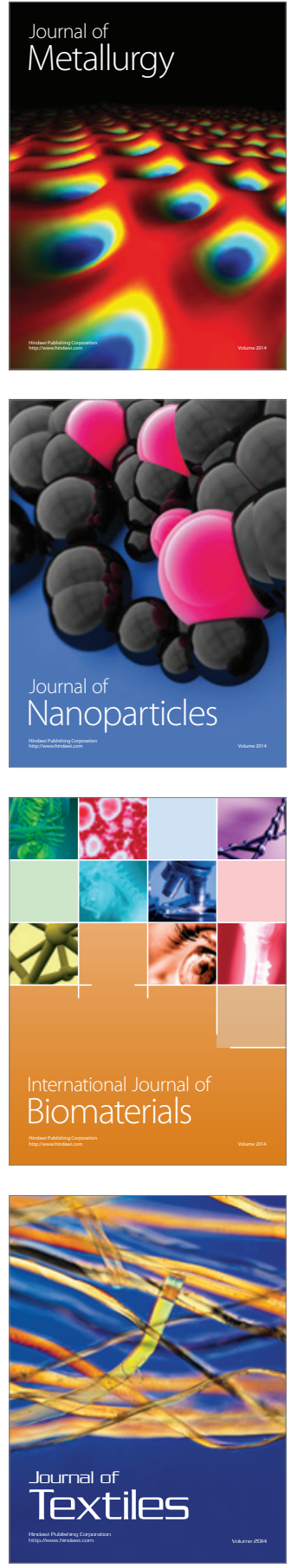